\title{
Influence Factors and Prediction Model of Bond Strength of Tunnel Fireproof Coating under Freeze-Thaw Cycles
}

\author{
Guanji Lu ${ }^{1, * \mathbb{C}}$, Tao $\mathrm{Ji}^{2}$, Binbin Zhang ${ }^{2}$, Yu Ma ${ }^{2}$ and Cong Liao ${ }^{2}$ \\ 1 Department of Management Engineering, Fujian Business University, Fuzhou 350012, China \\ 2 College of Civil Engineering, Fuzhou University, Fuzhou 350108, China; jt72@fzu.edu.cn (T.J.); \\ ZBB102766@163.com (B.Z.); benxiaohao2021@163.com (Y.M.); Liaoc2003@163.com (C.L.) \\ * Correspondence: lvguan@fjbu.edu.cn
}

Citation: Lu, G.; Ji, T.; Zhang, B.; Ma Y.; Liao, C. Influence Factors and

Prediction Model of Bond Strength of Tunnel Fireproof Coating under Freeze-Thaw Cycles. Materials 2021, 14, 1544. https://doi.org/10.3390/ ma14061544

Academic Editor:

Francesco Fabbrocino

Received: 5 February 2021

Accepted: 15 March 2021

Published: 22 March 2021

Publisher's Note: MDPI stays neutral with regard to jurisdictional claims in published maps and institutional affiliations.

Copyright: () 2021 by the authors. Licensee MDPI, Basel, Switzerland. This article is an open access article distributed under the terms and conditions of the Creative Commons Attribution (CC BY) license (https:// creativecommons.org/licenses/by/ $4.0 /)$.

\begin{abstract}
The freeze-thaw resistant performance of a tunnel fireproof coating (TFC) has an important impact on bonding property and durability. The influence of redispersible emulsion powder, polypropylene fiber and air-entraining agent on TFCs was studied. Transverse fundamental frequency and ultrasonic sound velocity were used to evaluate the damage degree of TFC, and the mechanism was revealed by SEM and pore structure. The results show that the most beneficial effect on bond strength of TFC is redispersible emulsion powder, followed by air-entraining agent, and then polypropylene fiber. After freeze-thaw cycles, the cumulative pore volume of micropores in the TFC increases obviously, while the porosity of macropores does not change significantly. A prediction model was proposed, which can calculate the bond strength from the damage degree of TFC under freeze-thaw cycles. The achievement can promote the application of TFC in cold regions.
\end{abstract}

Keywords: tunnel fireproof coating; bond strength; prediction model; pore structure; freeze-thaw cycles

\section{Introduction}

At present, the main measure for tunnel structure fire protection uses a fireproof coating (TFC) as the tunnel structure fire-resistance layer. Research on the cohesiveness, water-resistance and fire-resistance of TFCs has made considerable progress. However, the problem of bonding performance of TFCs in tunnels under freeze-thaw cycles is raised together with the problem of disease in tunnels. When a TFC suffers freeze damage, the TFC expands and then begins to loosen, piles up, or even peels off under repeated freezethaw action. This not only makes the TFC not only unable to play a fire insulation function but also becomes a tunnel safety hazard. Therefore, it is necessary to study the relationship between bonding performance and damage of TFC under freeze-thaw cycles.

The fireproof tunnel coating is a coating product specifically for tunnel fireproofing, along with the development history of the fireproof coating. The development of fireproof coatings began with the first fireproof coatings developed by Louis Pacmboenf in 1837 [1]. With the growth of time, several studies on the performance of tunnel fireproof coatings were found in the literature [2-9]. Weil. E et al. [10] developed new inorganic building fireproof coatings based on cement, inorganic mineral fiber, expanded perlite, expanded vermiculite and light calcium carbonate. Kidder et al. [11] developed fireproof coatings with excellent thermal insulation and explosion-proof performance for high alumina cement, fiber, sepiolite, calcium silicate and amorphous silica for tunnel structures and building exterior walls. The previous studies only focus on another durability of fireproof coatings, while the study of freezing damage to tunnel fireproof coatings is relatively rare. Meanwhile, the Chinese standard [12] stipulates that the bond strength of the coating shall be not less than $0.15 \mathrm{MPa}$ after 15 freeze-thaw cycles.

At present, there are few studies on freeze-thaw damage of tunnel fireproof coatings, and no literature on freeze-thaw damage of tunnel fireproof coatings has been found. Many scholars [13-28] have established an elastoplastic damage model for predicting frost 
resistance of concrete by introducing the plastic increment theory of stiffness, strength degradation and residual deformation. Cai Hao [29] proposed a theoretical damage model on the basis of Loland's unidirectional tensile damage evolution model; on the basis of regression analysis of material parameters, some empirical models were obtained, such as the concrete durability index relationship established by $\mathrm{Xu}$ Liping [30] considered the air content. In short, there is no relevant research on the prediction model between bond strength and damage degree of TFC. In fact, if the freeze-thaw damage law of TFC is clear, the development law of TFC performance (such as bond strength) can be analyzed, and the corresponding prediction formula of frost resistance performance can be obtained, which has a guiding role for the practical engineering application of TFC.

Some scholars [31-33] have studied the bond properties of TFC without freeze-thaw cycles, but there is little research on the bond performance after freeze-thaw cycles. The paper investigates the effects of redispersible emulsion powder, polypropylene fiber and air-entraining agent on the performance of TFC under freeze-thaw cycles. Transverse fundamental frequency and ultrasonic sound velocity were used to evaluate the damage degree of TFC. ESEM was used to analyze the changes of macro and micropore structure in TFC, and the mechanism of bond performance under freeze-thaw cycle was explained. Meanwhile, the model between bond performance and damage degree is established. The achievement of this paper can promote the application of TFC in cold regions.

\section{Experimental}

\subsection{Materials}

The fineness of polyvinyl alcohol (PVA) is $0.090-0.110 \mathrm{~mm}$, which is a white powder, odorless and tasteless. The air-entraining agent is a white powder used to improve the freeze-thaw resistance of coatings. It is made in Basel, Switzerland, and the best content is $0.01-0.03 \%$. The technical parameters of cement, high-alumina cement, redispersible emulsion powder and polypropylene fiber are shown in Tables 1-5, and their source information can be found in this article [34]. The technical parameters and source information of other material, including polyvinyl alcohol, polyvinyl alcohol silyl powder, expanded vermiculite, expanded perlite, sepiolite, hollow floating bead, $\mathrm{Mg}(\mathrm{OH})_{2}, \mathrm{Al}(\mathrm{OH})_{2}$, melamine, pentaerythritol, can be found in the paper [34].

Table 1. Performance indexes of P.O.42.5R cement.

\begin{tabular}{|c|c|c|c|c|c|c|c|}
\hline \multirow{2}{*}{$\begin{array}{l}\text { Apparent Density } \\
\left(\mathrm{kg} / \mathrm{m}^{3}\right)\end{array}$} & \multirow{2}{*}{$\begin{array}{c}\text { Specific Surface } \\
\text { Area }\left(\mathrm{m}^{2} / \mathrm{kg}\right)\end{array}$} & \multirow{2}{*}{$\begin{array}{c}\text { Loss on } \\
\text { Ignition }(\%)\end{array}$} & \multirow{2}{*}{$\begin{array}{c}\text { Initial/Final } \\
\text { Setting Time/min }\end{array}$} & \multicolumn{2}{|c|}{$\begin{array}{l}\text { Flexural Strength } \\
\text { (MPa) }\end{array}$} & \multicolumn{2}{|c|}{$\begin{array}{c}\text { Compressive Strength } \\
\text { (MPa) }\end{array}$} \\
\hline & & & & $3 d$ & $28 d$ & $3 d$ & $28 d$ \\
\hline 3050 & 360 & 1.06 & $125 / 185$ & 5.7 & 8.4 & 27.5 & 45 \\
\hline
\end{tabular}

Table 2. Composition of P.O.42.5R cement.

\begin{tabular}{ccccccc}
\hline Components & Clinker & Gypsum Dihydrate & Fly Ash & Limestone & Slag \\
\hline Content $(\%)$ & 82.5 & 5.5 & 4.0 & 4.0 & 4.0 & \\
\hline
\end{tabular}

Table 3. Composition of high-alumina cement.

\begin{tabular}{cccccc}
\hline Components & $\mathrm{SiO}_{2}$ & $\mathrm{Al}_{2} \mathbf{O}_{\mathbf{3}}$ & $\mathrm{Fe}_{\mathbf{2}} \mathbf{O}_{\mathbf{3}}$ & $\mathbf{R}_{\mathbf{2}} \mathbf{O}$ & Others \\
\hline Content $(\%)$ & 7.41 & 51.10 & 2.19 & 0.32 & 38.98 \\
\hline
\end{tabular}


Table 4. Physical and chemical properties of redispersible emulsion powder.

\begin{tabular}{cccccc}
\hline Solid Content (\%) & $\begin{array}{c}\text { Specific Gravity } \\
(\mathbf{m L} / \mathbf{g})\end{array}$ & Ash Content (\%) & $\begin{array}{c}\text { Glass Transition } \\
\text { Temperature }\left({ }^{\circ} \mathbf{C}\right)\end{array}$ & Particle Size (mm) & Viscosity (cps) \\
\hline $99 \pm 1$ & 7.41 & $10 \pm 2$ & -4 & 0.115 & $10 \mathrm{~s}(1 \%)$ \\
\hline
\end{tabular}

Table 5. Main technical indexes of polypropylene fiber.

\begin{tabular}{cccc}
\hline Item & Specifications & Item & Specifications \\
\hline Fiber diameter & $30 \mu \mathrm{m}$ & Fiber length & $6 \mathrm{~mm}$ \\
Tensile strength & $\geq 350 \mathrm{MPa}$ & Tensile break strength & $>15 \%$ \\
Melting point & $165-175^{\circ} \mathrm{C}$ & Ignition point & $590{ }^{\circ} \mathrm{C}$ \\
Density & $0.91 \mathrm{~kg} / \mathrm{m}^{3}$ & Dispersion & Excellent \\
Acid and alkali resistance & Strong & Aging resistance & Strong \\
Electrical conductivity & Low & Security & Non-toxic \\
\hline
\end{tabular}

\subsection{Test Mix Proportion}

The content of redispersible emulsion powder $\left(\alpha_{1}\right)$ was $0 \%, 2 \%$ and $4 \%$, respectively. The polypropylene fiber content $\left(\alpha_{2}\right)$ was $0 \%, 0.2 \%$ and $0.4 \%$, respectively. The content of air-entraining agent $\left(\alpha_{3}\right)$ was $0 \%, 0.015 \%$ and $0.030 \%$, respectively. The parameter level and test mix proportion are shown in Tables 6 and 7, respectively. The dry material (M) is the sum of the mass of M1-M15 in Table 6. The sum of M1-M15 is 100\%, and the air-entraining agent was mixed externally; others were mixed internally.

$$
\begin{aligned}
& \alpha_{1}=\mathrm{m}_{1} / \mathrm{M} \\
& \alpha_{2}=\mathrm{m}_{2} / \mathrm{M} \\
& \alpha_{3}=\mathrm{m}_{3} / \mathrm{M}
\end{aligned}
$$

$\mathrm{m}_{1}, \mathrm{~m}_{2}$ and $\mathrm{m}_{3}$ are the mass of redispersible emulsion powder, polypropylene fiber and

\begin{tabular}{|c|c|c|c|c|}
\hline \multicolumn{2}{|c|}{ Parameter } & $\alpha_{1}$ & $\alpha_{2}$ & $\alpha_{3}$ \\
\hline \multirow{3}{*}{ Level } & 1 & $0 \%$ & $0 \%$ & $0 \%$ \\
\hline & 2 & $2 \%$ & $0.2 \%$ & $0.015 \%$ \\
\hline & 3 & $4 \%$ & $0.4 \%$ & $0.030 \%$ \\
\hline
\end{tabular}
air-entraining agent, respectively.

Table 6. Parameter levels.

\begin{tabular}{|c|c|c|c|c|c|c|c|c|c|c|c|c|c|c|c|c|}
\hline Sample & M1 & M2 & M3 & M4 & M5 & M6 & M7 & M8 & M9 & M10 & M11 & M12 & M13 & M14 & M15 & M16 \\
\hline D1 & 35.10 & 5.10 & 1.22 & 0.51 & 15.41 & 12.96 & 7.76 & 2.55 & 3.27 & 9.90 & 1.02 & 2.04 & 2.96 & 0 & 0.2 & 0.015 \\
\hline D2 & 34.47 & 5.01 & 1.20 & 0.50 & 15.13 & 12.72 & 7.61 & 2.50 & 3.21 & 9.72 & 1.00 & 2.01 & 2.91 & 2 & 0 & 0.015 \\
\hline D3 & 34.40 & 5.00 & 1.20 & 0.50 & 15.10 & 12.70 & 7.60 & 2.50 & 3.20 & 9.70 & 1.00 & 2.00 & 2.90 & 2 & 0.2 & 0.030 \\
\hline $\mathrm{D} 4$ & 34.40 & 5.00 & 1.20 & 0.50 & 15.10 & 12.70 & 7.60 & 2.50 & 3.20 & 9.70 & 1.00 & 2.00 & 2.90 & 2 & 0.2 & 0.015 \\
\hline D5 & 33.69 & 4.90 & 1.18 & 0.49 & 14.79 & 12.44 & 7.44 & 2.45 & 3.13 & 9.50 & 0.98 & 1.96 & 2.84 & 4 & 0.2 & 0.015 \\
\hline D6 & 34.33 & 4.99 & 1.20 & 0.50 & 15.07 & 12.67 & 7.58 & 2.49 & 3.19 & 9.68 & 1.00 & 2.00 & 2.89 & 2 & 0.4 & 0.015 \\
\hline D7 & 34.40 & 5.00 & 1.20 & 0.50 & 15.10 & 12.70 & 7.60 & 2.50 & 3.20 & 9.70 & 1.00 & 2.00 & 2.90 & 2 & 0.2 & 0 \\
\hline
\end{tabular}

Table 7. Test mix proportions of tunnel fireproof coatings (TFC) (\%).

Note: M1-M16 in the table correspond to P.O. 42.5, high-alumina cement, polyvinyl alcohol, polyvinyl alcohol silyl powder, expanded vermiculite, expanded perlite, sepiolite, hollow floating bead, $\mathrm{Mg}(\mathrm{OH})_{2}, \mathrm{Al}(\mathrm{OH})_{2}$, melamine, pentaerythritol, ammonium polyphosphate, redispersible emulsion powder, polypropylene fiber and air-entraining agent, respectively. 


\subsection{Specimen Preparation and Test Methods}

\subsubsection{Freeze-Thaw Cycles Test}

There were three kinds of specimens subjected to the freeze-thaw cycle, namely, plate specimens, bond strength specimens and cube specimens. The size of the plate specimen was $150 \mathrm{~mm} \times 70 \mathrm{~mm} \times 6 \mathrm{~mm}$, the thickness of the TFC was $(5 \pm 1) \mathrm{mm}$. Three of each sample were used to observe whether the coating was cracked, peeled or discolored during the freeze-thaw cycles. The bond strength specimen included the base plate and TFC. The base plate size of the bond strength specimen was $70 \mathrm{~mm} \times 70 \mathrm{~mm} \times 6 \mathrm{~mm}$, the TFC thickness was $(5 \pm 1) \mathrm{mm}$, and the number of each specimen was 3 . The cube specimen was $100 \mathrm{~mm} \times 100 \mathrm{~mm} \times 100 \mathrm{~mm}$, and the number of each sample was 3 . It was used to measure the mass of TFC, transverse fundamental frequency and ultrasonic velocity under freeze-thaw cycle. The preparation process of specimens met the relevant Chinese standards [35].

\subsubsection{Mass Loss Rate Test}

At the end of the freeze-thaw cycles, we took out the specimen and dried the surface. We measured the mass and calculated the mass-loss rate according to the standard formula [12]. We calculated the mass-loss rate as the ratio of mass-loss to initial mass after freeze-thaw cycles.

\subsubsection{Damage Degree Test}

A DT-20 dynamic elastic instrument (made in Gangyuan test instrument factory, Tianjin, China) was used to measure the transverse fundamental frequency of TFC according to the standard of China [35]. An NM-4A nonmetal ultrasonic testing analyzer (made in Kangkerui company, Beijing, China) was used to obtain ultrasonic velocity.

\subsubsection{Bond Strength Test}

The test instrument was made in Beijing, China. The test method was in accordance with the requirements of Chinese standards [36].

\subsubsection{Test Method of Pore Structure}

The micropore structure was determined by the nitrogen adsorption method. Fsorb2800 pore structure analyzer was used in the test, which was made in Kingalp company, Beijing, China. The test sample was crushed into particles with a diameter of about $3 \mathrm{~mm}$. After weighing with an electronic balance, we took about $3 \mathrm{~g}$ of sample particles and put them into the sample tube. The macropore structure was processed by Matlab image processing technology, and the sample was sliced from the TFC before and after freeze-thaw cycle. The camera used in the experiment was Nikon d7000 SLR.

\subsubsection{Environmental Scanning Electron Microscope Test (ESEM)}

The samples were made into $10 \mathrm{~mm} \times 10 \mathrm{~mm} \times 10 \mathrm{~mm}$ according to the mix proportion of the D4 sample in Table 7, and the ESEM test was carried out after curing for $28 \mathrm{~d}$. The type of environmental scanning electron microscope is XL30, which was produced in FEI company, Holland.

\section{Results and Discussion}

\subsection{Bond Strength}

The variation rules of bond strength of coatings under freeze-thaw cycles are shown in Figure 1a by comparing the samples of D1, D4 and D5. Only the content of redispersible emulsion powder changed; the other two factors remained unchanged in Figure 1a. When the content of redispersible emulsion powder increased from $0 \%$ to $2 \%$ and $4 \%$, the initial bond strength of coatings increased by $73.0 \%$ and $90.2 \%$, respectively, indicating that the redispersible emulsion powder was beneficial to improve the initial bond strength of coatings. When the freeze-thaw cycles were up to 15 times, the bond strength with $0 \%$, 
$2 \%$ and $4 \%$ redispersed emulsion powder was $0.098 \mathrm{MPa}, 0.221 \mathrm{MPa}$ and $0.257 \mathrm{MPa}$, which decreases by $52.0 \%, 37.4 \%$ and $33.8 \%$ compared with the initial bond strength, respectively. When freeze-thaw cycles were up to 30 times, the bond strength with $0 \%, 2 \%$ and $4 \%$ redispersible emulsion powder was $0.039 \mathrm{MPa}, 0.151 \mathrm{MPa}$ and $0.170 \mathrm{MPa}$, which decreased by $81.2 \%, 57.1 \%$ and $56.0 \%$ compared with the initial bond strength, respectively. This indicated that the addition of redispersible emulsion powder could improve not only the initial bonding strength of the coating but also benefitted the frost-resistance of the TFC.

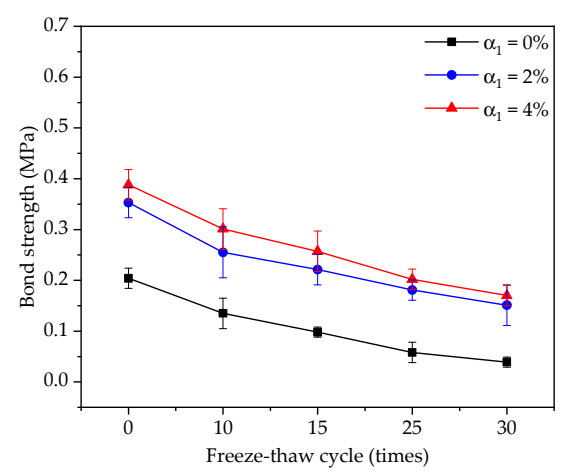

(a)

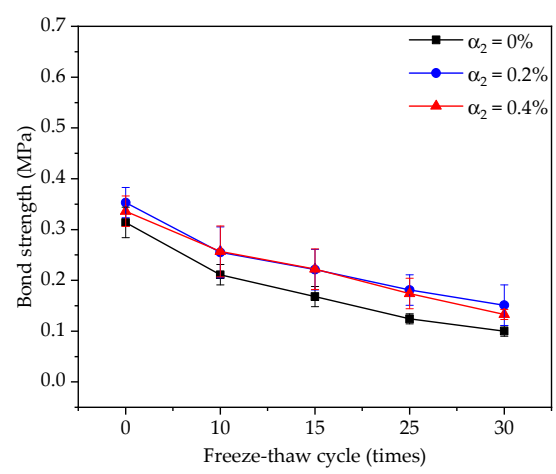

(b)

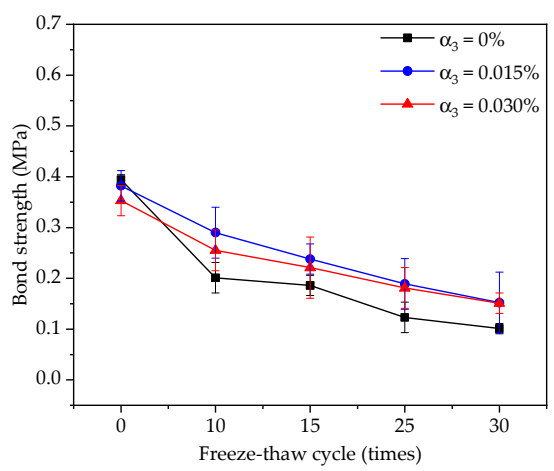

(c)

Figure 1. Influence of three factors on bond strength: (a) the factor of redispersible emulsion powder; (b) the factor of polypropylene fiber; (c) the factor of air-entraining agent.

The variation rules of bond strength of coatings under freeze-thaw cycles are shown in Figure $1 \mathrm{~b}$ by comparing the samples of D2, D4 and D6. Only the content of polypropylene fiber changed; the other two factors remained unchanged in Figure $1 \mathrm{~b}$. The initial bond strength of TFC with the polypropylene fiber content of $0 \%, 0.2 \%$ and $0.4 \%$ were $0.314 \mathrm{MPa}$, $0.353 \mathrm{MPa}$ and $0.336 \mathrm{MPa}$, respectively. When the content of polypropylene fiber was from $0 \%$ to $2 \%$ and $4 \%$, the initial bond strength increased by $12.4 \%$ and $7.0 \%$, respectively. With the increase of freeze-thaw cycle, the bonding strength of TFC decreased. When the freeze-thaw cycles reached 30 times, the bond strength of TFC with $0 \%, 0.2 \%$ and $0.4 \%$ polypropylene fibers was $0.100 \mathrm{MPa}, 0.151 \mathrm{MPa}$ and $0.133 \mathrm{MPa}$, respectively, which decreased by $68.1 \%, 57.1 \%$ and $60.6 \%$ compared with the corresponding initial bond strength, respectively.

The variation rules of bond strength of coatings under freeze-thaw cycles are shown in Figure 1c by comparing the samples of D3, D4 and D7. Only the content of the airentraining agent changed; the other two factors remained unchanged in Figure 1c. The initial bond strength of the coating was $0.394 \mathrm{MPa}, 0.382 \mathrm{MPa}$ and $0.353 \mathrm{MPa}$, with a slight decrease when the content of the air-entraining agent increased from $0 \%$ to $0.015 \%$ and $0.030 \%$. With the increase of freeze-thaw cycles, the bonding strength of TFC decreased. When the freeze-thaw cycles were up to 15 times, the bond strength of TFC under the three concentrations of $0 \%, 0.015 \%$ and $0.030 \%$ of the air-entraining agent was $0.201 \mathrm{MPa}$, $0.290 \mathrm{MPa}$ and $0.255 \mathrm{MPa}$, respectively, which decreased by $52.9 \%, 37.6 \%$ and $37.3 \%$, compared with the corresponding initial bond strength. When freeze-thaw cycles reached 30 times, the bond strength of coatings with $0 \%, 0.015 \%$ and $0.030 \%$ dosage was $0.101 \mathrm{MPa}$, $0.152 \mathrm{MPa}$ and $0.151 \mathrm{MPa}$, which decreased by $74.3 \%, 60.2 \%$ and $57.1 \%$, compared with the corresponding initial bond strength.

\subsection{Mass Loss Rate}

The variation rules of mass-loss rate of the coating under freeze-thaw cycles are shown in Figure 2a by comparing the samples of D1, D4 and D5. Only the content of redispersible emulsion powder changed; the other two factors remained unchanged in Figure 2a. When the freeze-thaw cycle was less than 10 times, the mass-loss rate of the coatings with 
$0 \%, 2 \%$ and $4 \%$ redispersible emulsion powder was almost the same. However, when the freeze-thaw cycles were more than 10 times, the mass-loss rate of the coating with $0 \%$ content was the largest, and the mass-loss rate of the coating with $2 \%$ and $4 \%$ content was almost the same, which was different only when the freeze-thaw cycles were about 25 times. The results show that the mass-loss rate of $2 \%$ and $4 \%$ redispersible emulsion was $10.6 \%$ and $31.7 \%$, respectively, compared with that of $0 \%$ in 15 and 30 freeze-thaw cycles. With the increase of freeze-thaw cycles, the mass-loss rate of the coating increased, but the mass-loss rate of $2 \%$ and $4 \%$ redispersible emulsion powder was obviously slower than that of $0 \%$.

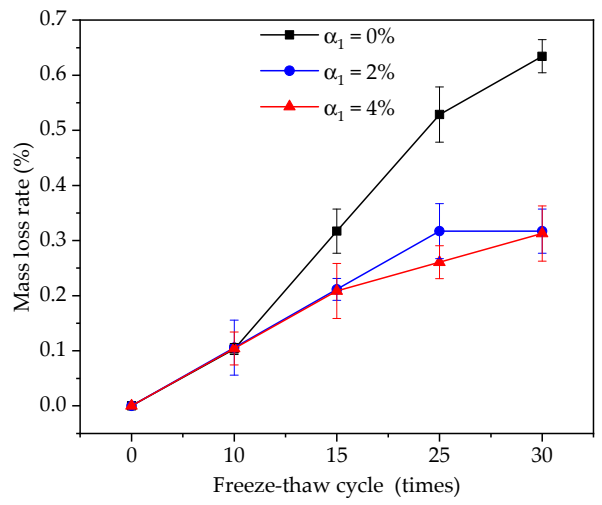

(a)

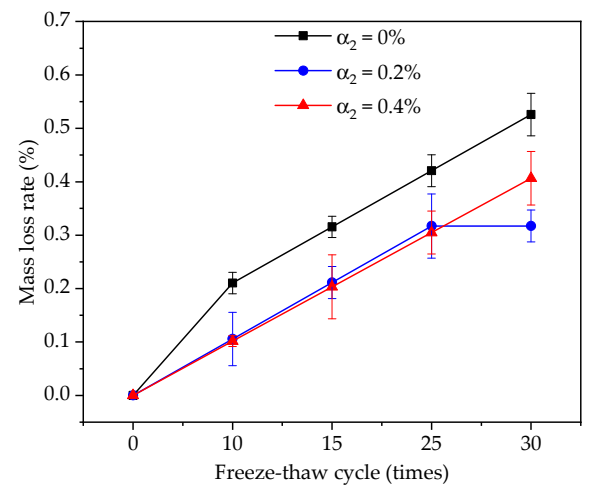

(b)

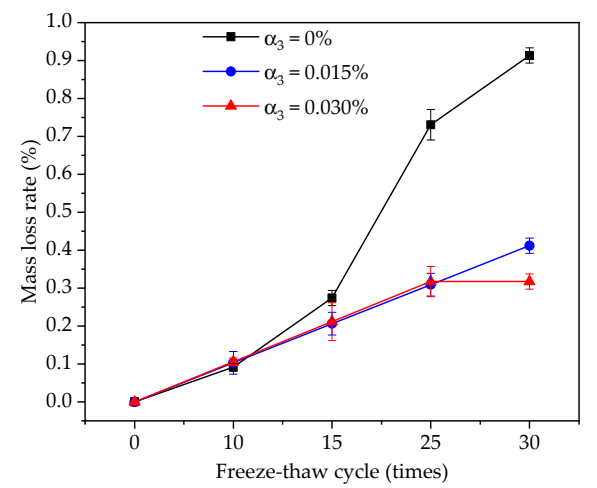

(c)

Figure 2. Influence of three factors on the mass-loss rate: (a) the factor of redispersible emulsion powder; (b) the factor of polypropylene fiber; (c) the factor of air-entraining agent.

The variation rules of mass-loss rate of coatings under freeze-thaw cycles are shown in Figure 2a by comparing the samples of D2, D4 and D6. Only the content of polypropylene fiber changed; the other two factors remained unchanged in Figure $2 b$. When the freezethaw cycle was 15 and 30 times, the mass-loss rate of the coating with a polypropylene fiber content of $0.2 \%$ was $10.4 \%$ and $20.9 \%$ less than that with $0 \%$, respectively. The mass-loss rate of the coating with a polypropylene fiber content of $0.2 \%$ and $0.4 \%$ was almost the same, only when the freeze-thaw cycle was 30 times. With the increase of freeze-thaw cycles, the mass-loss rate of the coating increased.

The variation rules of mass-loss rate of coatings under freeze-thaw cycles are shown in Figure 2c by comparing the samples of D3, D4 and D7. Only the content of the airentraining agent changed; the other two factors remained unchanged in Figure 2c. When the freeze-thaw cycle was less than 10 times, the mass-loss rate of the coatings with $0 \%$, $0.015 \%$ and $0.030 \%$ air-entraining agent was almost the same. However, when the freezethaw cycles were more than 10 times, the mass-loss rate of the coating with $0 \%$ content was the largest, and the mass-loss rate of the coating with $0.015 \%$ and $0.030 \%$ content was almost the same, which was different only when the freeze-thaw cycles reached 30 times. With the increase of freeze-thaw cycles, the mass-loss rate of the coating increased, but the mass-loss rate of $0.015 \%$ and $0.030 \%$ air-entraining agent was obviously slower than that of $0 \%$.

\subsection{Damage Degree}

The variation rules of damage degree of coatings under freeze-thaw cycles are shown in Figure 3a by comparing the samples of D1, D4 and D5. Only the content of redispersible emulsion powder changed; the other two factors remained unchanged in Figure 2a. The changed rule of $D_{L}$ and Dc was basically the same, and it increased with the increase of freeze-thaw cycles. At 15 and 30 freeze-thaw cycles, the damage degree of $2 \%$ redispersible latex powder was 0.029 and 0.36 less than that of $0 \%$, respectively. When the freeze-thaw cycle was 30 times, the damage degree of TFC with redispersible emulsion powder content 
of $0 \%$ was about three times compared with that of $4 \%$. The damage degree of $2 \%$ and $4 \%$ redispersible emulsion powder was almost the same.

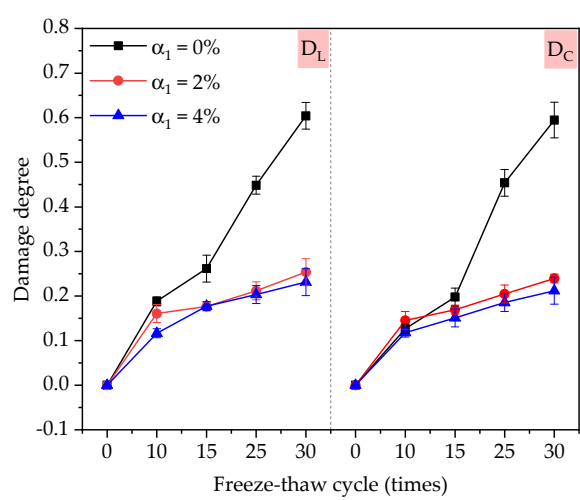

(a)

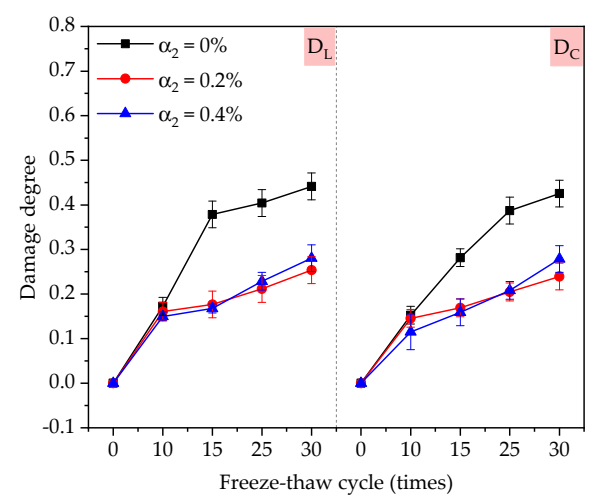

(b)

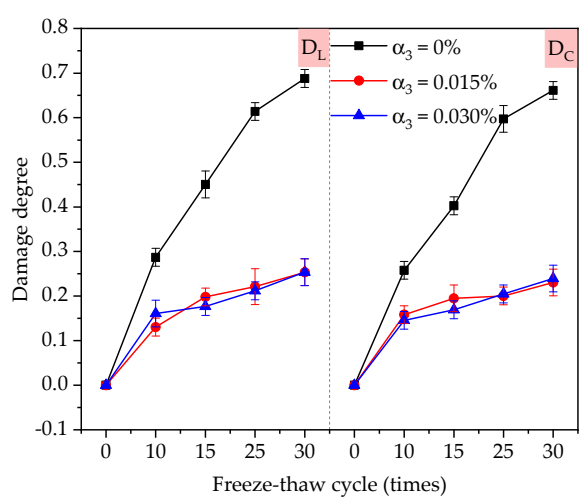

(c)

Figure 3. Influence of three factors on damage degree: (a) the factor of redispersible emulsion powder; (b) the factor of polypropylene fiber; (c) the factor of air-entraining agent. $\mathrm{D}_{\mathrm{L}}$ : damage degree measured by transverse fundamental frequency; $\mathrm{D}_{\mathrm{C}}$ : damage degree measured by supersonic velocity.

The variation rules of damage degree of coatings under freeze-thaw cycles are shown in Figure $2 \mathrm{~b}$ by comparing the samples of D2, D4 and D6. Only the content of polypropylene fiber changed; the other two factors remained unchanged in Figure $2 \mathrm{~b}$. Polypropylene fiber could reduce the damage of TFC in freeze-thaw cycles, but when the content of polypropylene fiber was greater than $0.2 \%$, the damage reduction effect was not obvious. When the freeze-thaw cycles were less than 10 times, the damage degree of the coatings with a polypropylene fiber content of $0 \%, 0.2 \%$ and $0.4 \%$ were close. When the freeze-thaw cycles were more than 10 times, the damage degree of the coating was greatly reduced when the polypropylene fiber content was $0.2 \%$.

The variation rules of damage degree of coatings under freeze-thaw cycles are shown in Figure 3c by comparing the samples of D3, D4 and D7. Only the content of the airentraining agent changed; the other two factors remained unchanged in Figure $3 c$. The changed rule of $D_{L}$ and Dc was basically the same. At 0,15 , and 30 freeze-thaw cycles, the damage degree of $0.015 \%$ air-entraining agent was 0.21 and 0.43 less than that of $0 \%$, respectively. Unlike redispersible emulsion powder and polypropylene fiber, the damage reduction effect of the air-entraining agent was already evident at the beginning of the freeze-thaw cycles.

\subsection{Microscopic Pores}

In Figure 4a, only the content of redispersible emulsion powder changed, while the content of other factors remained unchanged. Others are also single factor changes in Figure $4 b, c$ and Figure $5 a-c$. When the content of redispersible emulsion powder increases from $0 \%, 2 \%$ to $4 \%$, the cumulative pore volume and average diameter decrease under the same freeze-thaw cycles (as shown in Figures $4 a$ and $5 a$ ). The redispersible emulsion powder is beneficial to improve the freeze-thaw resistance of coatings. Under the same freeze-thaw cycles, the larger the content of redispersible emulsion powder, the smaller the cumulative pore volume and average diameter of micropore. 


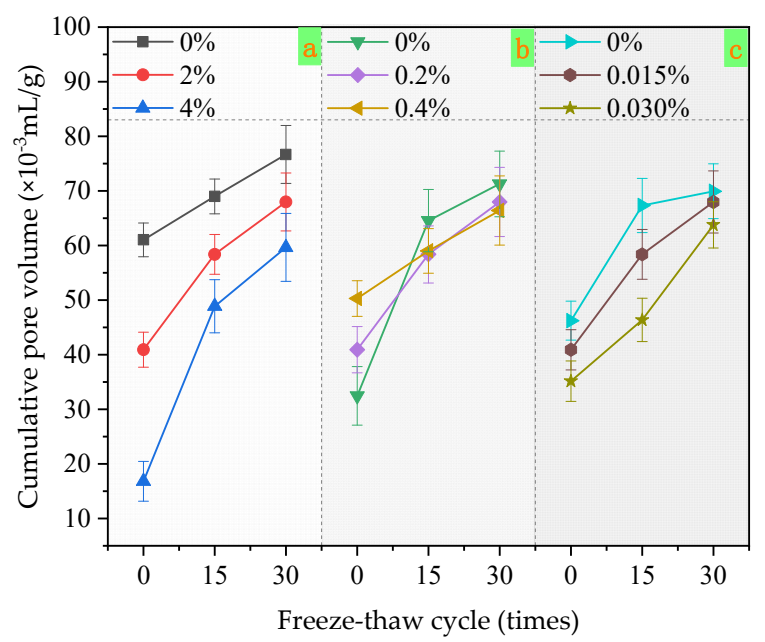

Figure 4. Influence of three factors on cumulative pore volume: (a) the factor of redispersible emulsion powder; (b) the factor of polypropylene fiber; (c) the factor of air-entraining agent.

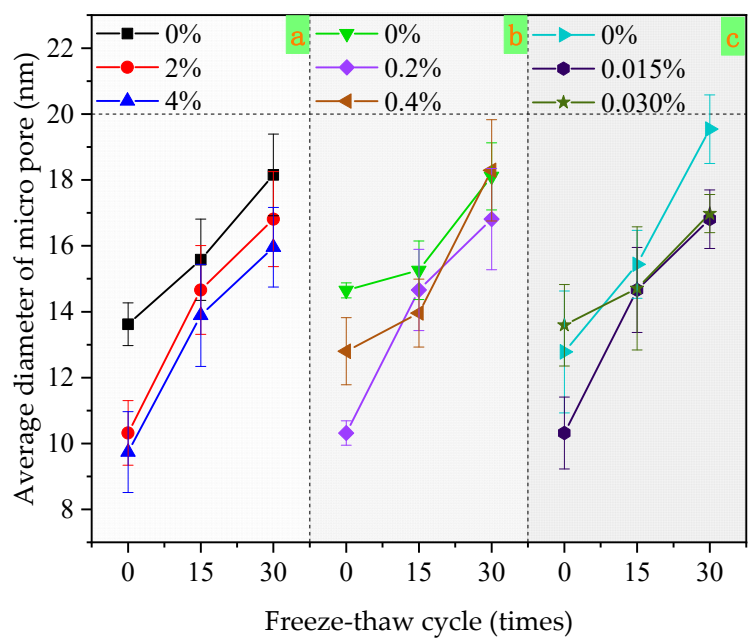

Figure 5. Influence of three factors on the average diameter of micropore: (a) the factor of redispersible emulsion powder; (b) the factor of polypropylene fiber; (c) the factor of air-entraining agent.

At 0 freeze-thaw cycles, the cumulative pore volume decreased with the increase of polypropylene fiber content. However, in 15 and 30 freeze-thaw cycles, the cumulative pore volume of the coatings with $0.4 \%$ polypropylene fiber content was larger than that with $0 \%$, and the cumulative pore volume of the coatings with $0.2 \%$ was basically the same as that with $0 \%$. The average diameter of micropore increased with the increase of freeze-thaw cycles. The average pore diameter of the coating with a polypropylene fiber content of $0.2 \%$ was the smallest at 0 and 30 freeze-thaw cycles. Moreover, the coating with $0.4 \%$ polypropylene fiber had the smallest average pore diameter in 15 freeze-thaw cycles. Moreover, when the content of polypropylene fiber was $0.2 \%$, the mass-loss rate and damage degree were reduced compared with that $0 \%$.

When the content of the air-entraining agent increased from $0 \%, 2 \%$, to $4 \%$, the cumulative pore volume decreased under the same freeze-thaw cycles. With the increase of freeze-thaw cycles, the cumulative pore volume and average diameter of the coating increase. The coating with $0.015 \%$ polypropylene fiber had the smallest average micropore diameter at 0 freeze-thaw cycles, but the coating with $0.015 \%$ polypropylene fiber had the same average micropore diameter as that with $0.030 \%$ at $15-30$ freeze-thaw cycles. 


\subsection{Macro Pores}

From Figure 6a, the average diameters of D1, D4 and D5 were $165.2 \mu \mathrm{m}, 163.7 \mu \mathrm{m}$, and $159.0 \mu \mathrm{m}$ under 0 freeze-thaw cycles, respectively, and the average diameters of D1, D4 and D5 were $181.3 \mu \mathrm{m}, 169.3 \mu \mathrm{m}$, and $169.2 \mu \mathrm{m}$ under 15 freeze-thaw cycles, respectively. The average diameters of D1, D4 and D5, increased by $9.75 \%, 3.42 \%$ and $6.41 \%$, respectively, when the freeze-thaw cycles increased from 0 to 15 times. The average diameters of macroscopic pores in TFC were $189.9 \mu \mathrm{m}, 180.6 \mu \mathrm{m}, 174.0 \mu \mathrm{m}$, and increased by $14.95 \%, 10.32 \%$ and $9.43 \%$ in 30 freeze-thaw cycles compared with 0 freeze-thaw cycles, respectively. The results show that the addition of redispersible emulsion powder improved the freeze-thaw resistance of macropores. From Figure 6b, at 0 and 15 freeze-thaw cycles, the porosity of the coating with $4 \%$ redispersible emulsion powder was the smallest, but at 30 freeze-thaw cycles, the porosity was the largest. From Figure 7, the proportion of large pore size increased slightly with the increase of freeze-thaw cycles. At 15 freeze-thaw cycles, the pore distribution of the D4 sample was $26.98 \%$ in the pore diameter range of $0.9-1.2 \mathrm{~mm}$.

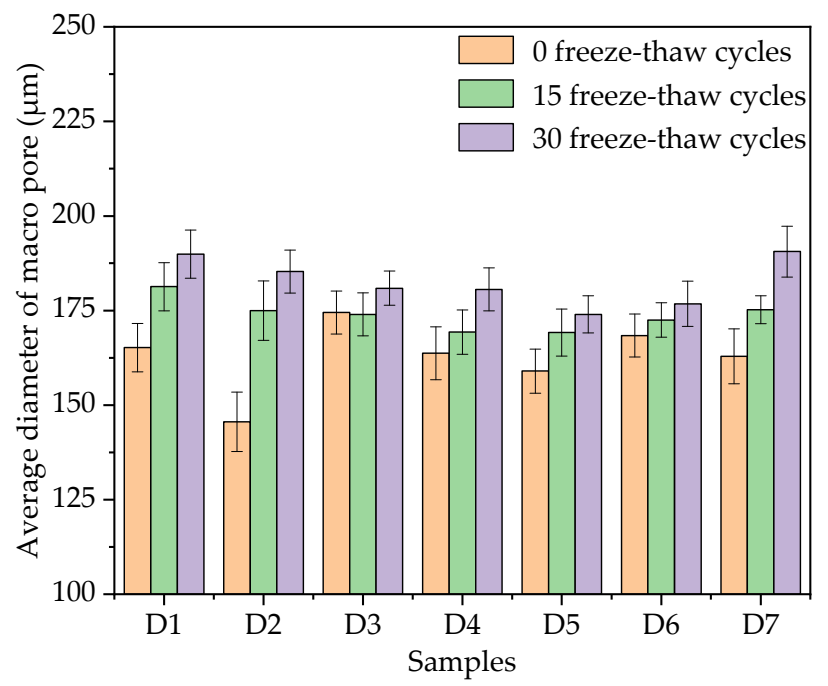

(a)

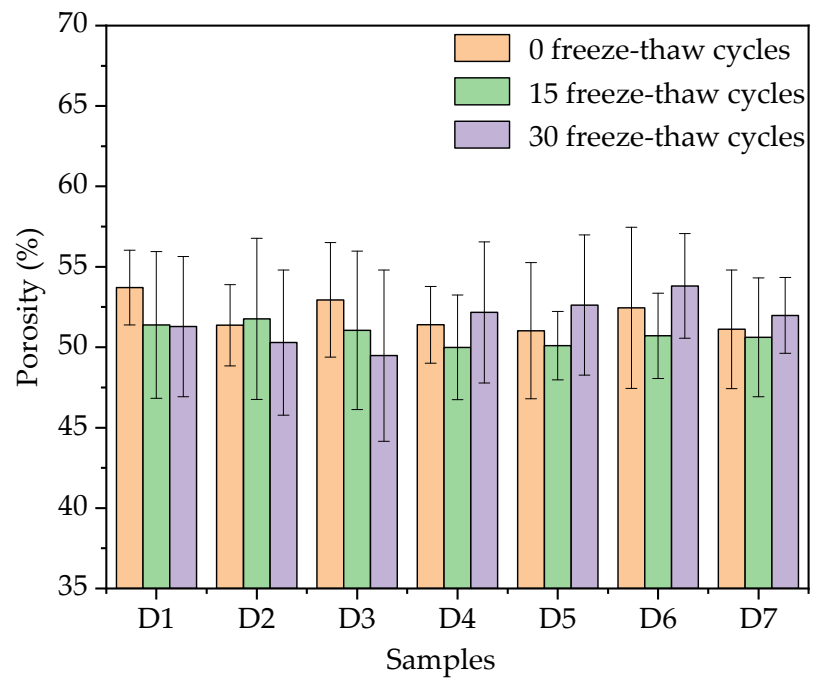

(b)

Figure 6. Average macroscopic pore diameter and porosity under freeze-thaw cycles: (a) average macroscopic pore diameter under freeze-thaw cycles; (b) porosity under freeze-thaw cycles.

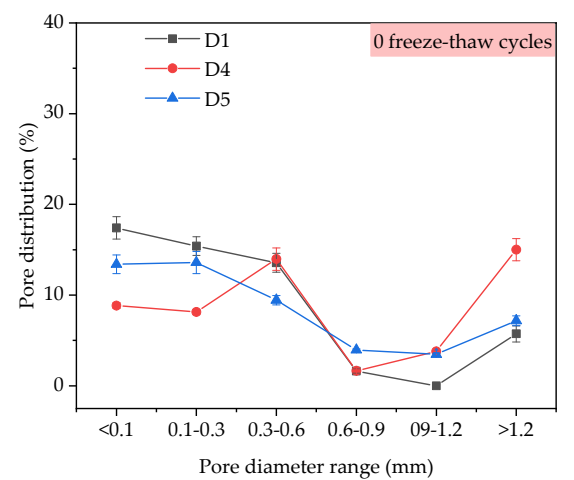

(a)

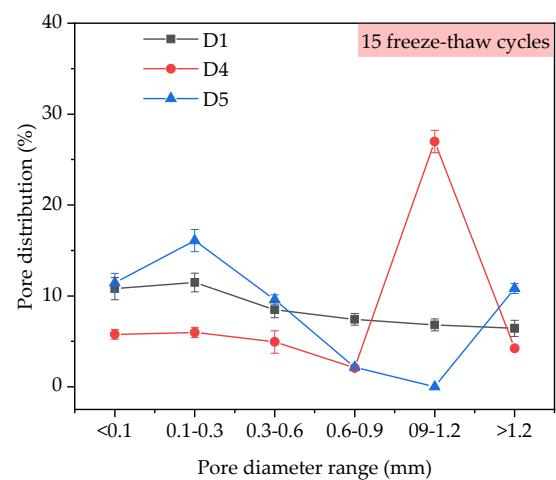

(b)

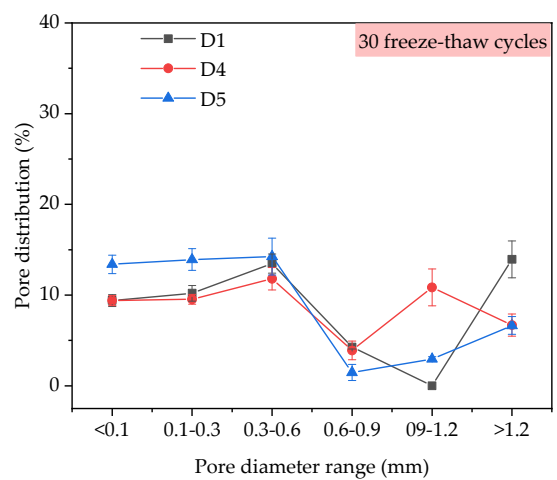

(c)

Figure 7. Pore distribution under the influence of redispersible emulsion powder: (a) 0 freeze-thaw cycles; (b) 15 freeze-thaw cycles; (c) 30 freeze-thaw cycles. 
By comparing D2, D4, and D6 samples in Figure 6a, when the polypropylene fiber content in TFC increased from $0 \%, 0.2 \%$ to $0.4 \%$ at 15 freeze-thaw cycles, the average diameters of the corresponding macroscopic pores in the coating were $175.0 \mu \mathrm{m}, 169.3 \mu \mathrm{m}$ and $172.5 \mu \mathrm{m}$, respectively, which were increased by $20.2 \%, 3.42 \%$ and $2.43 \%$ compared with $145.6 \mu \mathrm{m}, 163.7 \mu \mathrm{m}$ and $168.4 \mu \mathrm{m}$ at 0 freeze-thaw cycles. When the polypropylene fiber content in TFC increased from $0 \%, 0.2 \%$ to $0.4 \%$ at 30 freeze-thaw cycles, the average diameters of the corresponding macroscopic pores in TFC were $185.3 \mu \mathrm{m}, 180.6 \mu \mathrm{m}$, and $176.8 \mu \mathrm{m}$, respectively, which were increased by $27.27 \%, 10.32 \%$ and $4.99 \%$ compared with 0 freeze-thaw cycles. From Figure $6 b$, at 0 and 15 freeze-thaw cycles, the porosity of the coating with $0.2 \%$ polypropylene fiber was the smallest, but at 30 freeze-thaw cycles, the porosity was the largest. From Figure 8, the proportion of large pore size increased with the increase of freeze-thaw cycles. At 0 freeze-thaw cycles, the pore distribution of the D6 sample was $42.26 \%$ in the pore diameter range of $0.1-0.3 \mathrm{~mm}$.

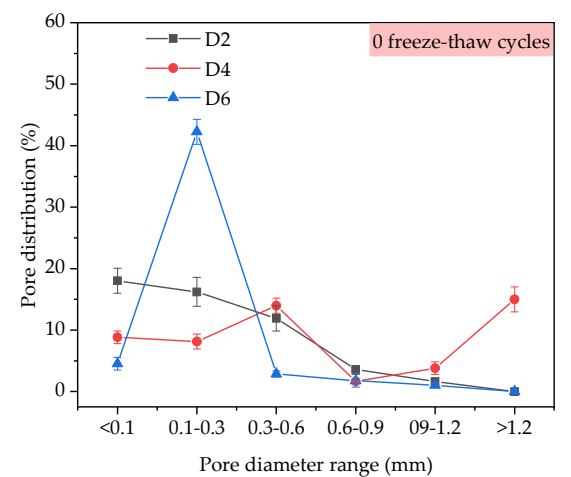

(a)

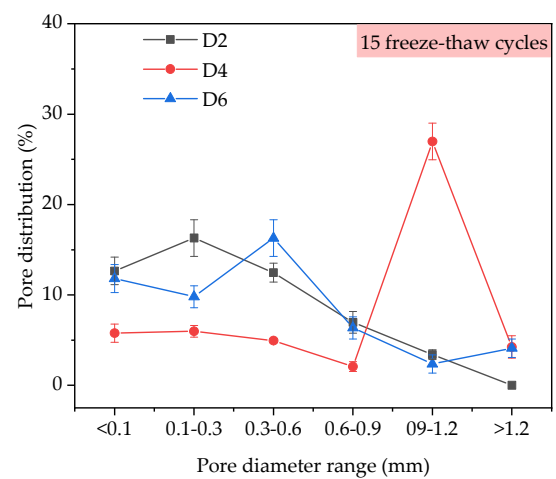

(b)

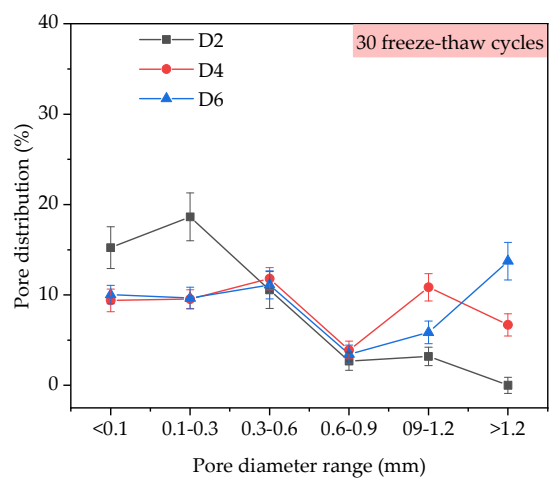

(c)

Figure 8. Pore distribution under the influence of polypropylene fiber: (a) 0 freeze-thaw cycles; (b) 15 freeze-thaw cycles; (c) 30 freeze-thaw cycles.

By comparing D3, D4 and D7 samples in Figure 6a, it was shown that the average diameter and porosity of macroscopic pores increased with the increase of the content of the air-entraining agent, which was mainly due to the introduction of bubbles with the diameter of 25-250 $\mu \mathrm{m}$ by the air-entraining agent. When freeze-thaw cycles reached 15 times, the average diameters of the corresponding macropores were $175.2 \mu \mathrm{m}, 169.3 \mu \mathrm{m}$ and $174.0 \mu \mathrm{m}$, which were increased by $7.55 \%, 3.42 \%$ and $0 \%$, respectively, compared with $162.9 \mu \mathrm{m}, 163.7 \mu \mathrm{m}$ and $174.5 \mu \mathrm{m}$ under 0 freeze-thaw cycles. When freeze-thaw cycles reached 30 times, the average diameters of the corresponding macroscopic pores were $190.6 \mu \mathrm{m}, 180.6 \mu \mathrm{m}$, and $180.9 \mu \mathrm{m}$, which were $17.00 \%, 10.32 \%$ and $3.67 \%$ higher than that under 0 freeze-thaw cycles, respectively. The air-entraining agent could still inhibit the deterioration of macropores, and it enhanced the freeze-thaw resistance of micropores of TFC. From Figure $6 \mathrm{~b}$, at 15 freeze-thaw cycles, the porosity of the coating with $0.015 \%$ air-entraining agent was the smallest, but it was only about $1 \%$ less than $0 \%$ and $0.030 \%$ content. From Figure 9, the pore distribution of the D7 sample with a pore diameter greater than $0.9 \mathrm{~mm}$ decreased significantly at 30 freeze-thaw cycles. 


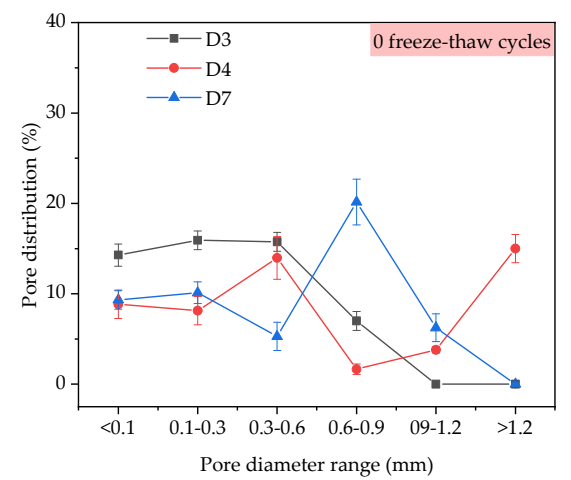

(a)

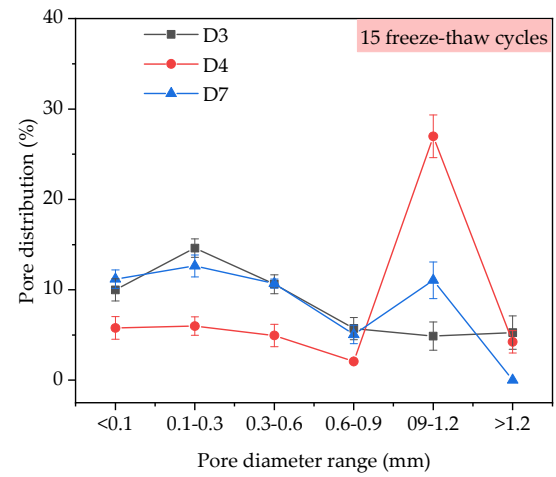

(b)

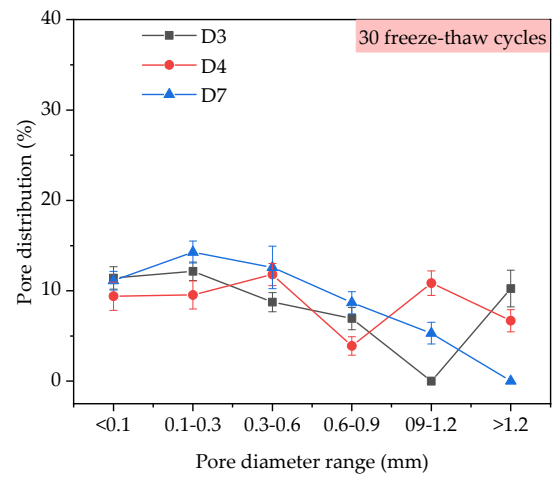

(c)

Figure 9. Pore distribution under the influence of air-entraining agent: (a) 0 freeze-thaw cycles; (b) 15 freeze-thaw cycles; (c) 30 freeze-thaw cycles.

\subsection{Mechanism Analysis}

The internal structure of the coating can be clearly seen in Figure 10. The addition of redispersible emulsion powder made the coating form a network structure, filled the internal pores and made it denser. Hence, from Figure $1 \mathrm{a}$, the maximum bond strength was obtained when the content of redispersible emulsion powder was $4 \%$ under the same freeze-thaw cycles. At the same time, the mass-loss rate and damage degree of the coating with $2 \%$ redispersible emulsion powder was also reduced compared with that of $0 \%$, according to Figures 2a and 3a. Moreover, from Figures 4 and 5 that the cumulative pore volume and pore diameter decreased with the increase of the content.

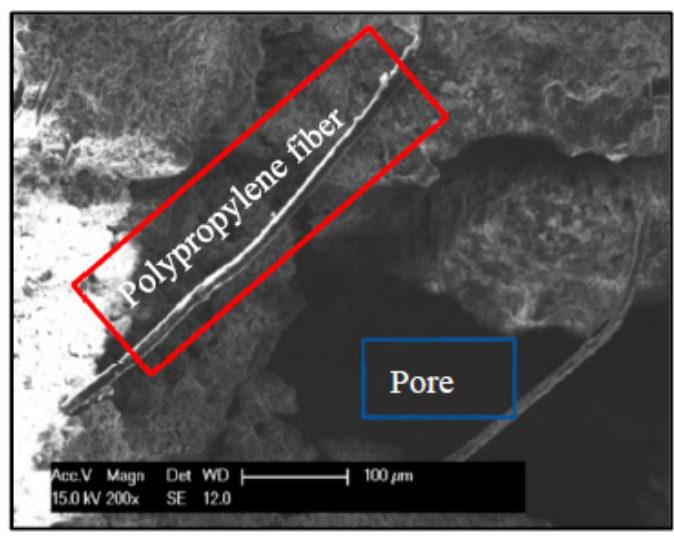

(a)

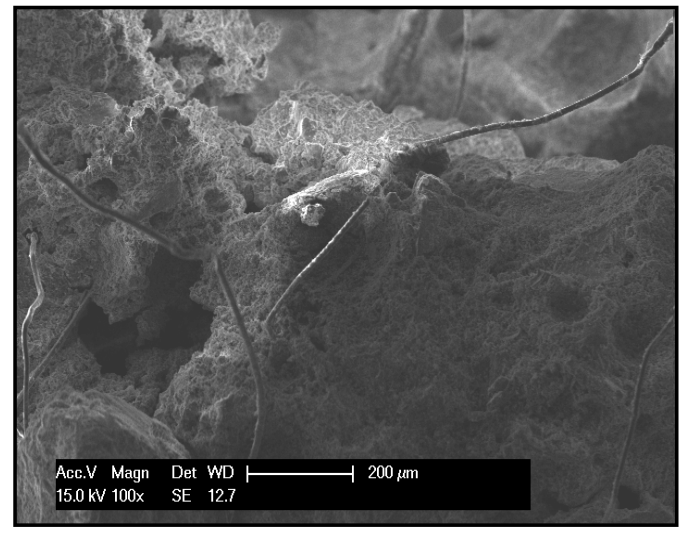

(b)

Figure 10. Environmental scanning electron microscope (ESEM) scanning electron microscope sampling: (a)enlargement of 200 times; (b)enlargement of 100 times.

From Figure 10, the long fibrous material is polypropylene fiber, which connects the internal structure of the coating to form a whole to resist stress damage. Polypropylene fiber not only can share part of frost heaving stress but also has good resistance to damage caused by freeze-thaw cycle. Moreover, it has a bridge effect on cement-based coatings, which makes the internal microcracks of TFC difficult to form and improves the bond strength of TFC. Hence, from Figure $1 b$, the bond strength of $0.2 \%$ polypropylene fiber was close to that of $0.4 \%$ but greater than that of $0 \%$.

The air-entraining agent introduced a large number of micropores, which can increase frost resistance. From Figure 10 that there were a large number of pores in the coating, but there were many small diameter pores. Air-entraining agent reduces the density of the coating, so the bond strength of $0.030 \%$ air-entraining agent was lower than that of 
$0.015 \%$ from Figure 1c. However, the damage degree and mass-loss rate decrease greatly under freeze-thaw cycles. The air-entraining agent could still inhibit the deterioration of macropores, and it could enhance the freeze-thaw resistance of micropores of TFC.

\subsection{Bond Strength Model}

After the parameter values of $p_{1}$ and $p_{2}$ were calculated by MATLAB (Equation (3)) according to the regression algorithm, the regression equations of Equations (5) and (6) could be obtained by lstopt software based on the universal global optimization (UGO).

$$
\sigma=p_{1} \ln (D)+p_{2}
$$

$$
\begin{gathered}
p_{1}=-0.0185-0.3969 \times \alpha_{1}-1.8437 \times \alpha_{2}+57.9833 \times \alpha_{3}+3.1625 \times \alpha_{1}{ }^{2}+343.745 \times \alpha_{2}{ }^{2}-125111.1111 \times \alpha_{3}{ }^{2} \\
p_{2}=0.0096+6.2645 \times \alpha_{1}+29.02 \times \alpha_{2}+445.6 \times \alpha_{3}-101.3750 \times \alpha_{1}{ }^{2}-5550.0 \times \alpha_{2}{ }^{2}-1129777.7778 \times \alpha_{3}{ }^{2}
\end{gathered}
$$

$\sigma$ is the bond strength; $D$ is the damage degree, taking the average value of $D_{L}$ and $D_{C} ; p_{1}$ and $p_{2}$ are regression parameters; $\alpha_{1}, \alpha_{2}$ and $\alpha_{3}$ respectively represent thecontents of redispersible emulsion powder, polypropylene fiber and air entraining agent.

\section{Conclusions}

(1) With the increase of freeze-thaw cycle, the bond strength of the coatings with the same content of redispersible emulsion powder decreased. The bond strength increased with the increase of redispersible emulsion powder content under the same freezethaw cycles. The mass-loss rate and damage degree of the coating with $2 \%$ and $4 \%$ redispersible emulsion powder were also reduced compared with that of $0 \%$;

(2) Polypropylene fibers not only can share part of frost heaving stress but also had good resistance to damage caused by freeze-thaw cycle. The bond strength of $0.2 \%$ polypropylene fiber was close to that of $0.4 \%$ but greater than that of $0 \%$;

(3) The bond strength of $0.030 \%$ air-entraining agent was lower than that of $0.015 \%$ but greater than that of $0 \%$. The damage degree and mass-loss rate decrease greatly under freeze-thaw cycles;

(4) In the freeze-thaw cycles, the most beneficial effect on the bond strength of coatings was redispersible emulsion powder, followed by air-entraining agent, and then polypropylene fiber;

(5) The mathematical model between bond strength and damage degree was established by Matlab.

Although there is a good correlation between bond strength and damage degree, further research is needed to verify and improve its reliability. In addition, a microscopic test was added to further study the mechanism of TFC.

Author Contributions: Conceptualization, T.J. and G.L.; methodology, G.L.; software, B.Z.; validation, G.L., and T.J.; formal analysis, G.L.; investigation, C.L. and Y.M.; resources, G.L.; data curation, C.L. and Y.M.; writing — original draft preparation, G.L.; writing-review and editing, Y.M.; visualization, G.L.; supervision, G.L.; project administration, T.J.; funding acquisition, G.L. All authors have read and agreed to the published version of the manuscript.

Funding: This research was funded by the 12th FIVE YEAR NATIONAL SCIENCE AND TECHNOLOGY SUPPORT PLAN, grant number 2012BAJ14B05. The APC was funded by FUJIAN SCIENCE AND TECHNOLOGY PROJECT, grant number 2020J01325.

Institutional Review Board Statement: Not applicable.

Informed Consent Statement: Not applicable.

Data Availability Statement: Data sharing not applicable.

Conflicts of Interest: The authors declare no conflict of interest. 


\section{References}

1. Wang, N.; Li, J.P.; Shi, Q. Research status and development of fire retardant coatings. J. Lanzhou Railw. Univ. 2002, 21, 106-108.

2. Liu, J.J. Current situation and development trend of fire retardant coatings. Fire Prot. Technol. Prod. Inf. 2004, 11, $28-31$.

3. Yang, Q. Research progress of intumescent fire retardant coatings. Chin. Coat. 2001, 4, 37-38.

4. Xue, E.Y.; Zeng, M.X. Flame Retardant Science and Its Application; National Defense Industry Press: Beijing, China, 1988.

5. Bains, R.S.; Cusack, P.A. An evaluation of the performance of tin-based flame-retardant paints. J. Oil Colour Chem. Assoc. 1990, 73, 340-343.

6. Yin, Q.S. Properties and application of flame retardant ammonium polyphosphate. Chem. World 1985, 3, 85-86.

7. Zhou, B. One Component Environmental Protection Tunnel Fire Retardant Coating; Hunan University: Changsha, China, 2012.

8. Gu, J.W. Development of Intumescent Fire Retardant Coatings; Northwest University of technology: Xi'an, China, 2006.

9. Cheng, X.W. Formulation design and performance research of tunnel fire retardant coating. Constr. Technol. 2005, 34, 73-75.

10. Weil, E.; Mcswigan, B. Melamine phosphates and polyphosphate in flame-retardant coatings: Old products with new potential. J. Coat. Technol. 1994, 66, 75-82.

11. Kidder, R. Handbook of Fire Retardant Coatings and Fire Testing Services; Technomic Pub. Co.: Lancaster, PA, USA, 1994.

12. GB National Standard. Fire Retardant Coatings for Concrete Structures; General Administration of Quality Supervision and Inspection of the People's Republic of China: Beijing, China, 2012; GB/T 28375-2012.

13. Lin, G.; Liu, J.; Hu, Z.Q. Research status and progress of concrete damage constitutive relation. J. Dalian Univ. Technol. 2010, 50, 1055-1064.

14. Mazars, J. Continuous damage theory-applicatin to concrete. J. Eng. Mech. 1980, 115, 345-365. [CrossRef]

15. Loland, K.E. Concrete damage model for load-response estimation of Concrete. Cem. Concr. Res. 1980, 10, 392-492. [CrossRef]

16. Krajcinovic, D.; Fonseka, G.U. The continuous damage theory of brittle materials. J. Appl. Mech. 1981, 48, 809-815. [CrossRef]

17. Janson, J.; Hult, J. Fracture mechanics and damage mechanics, a combined approach. J. Appl. Mech. 1997, 1, 59-64.

18. Hult, J. Introduction and overview. In Continuum Damage Mechanics: Theory and Applications; Springer: New York, NY, USA, 1989.

19. Lemaitre, J.; Chaboehe, J. Aspect phenomenological delay rupture pare endommagement. J. Appl. Mech. 1978, 12, 317-365.

20. Lemaitre, J.; Plumtree, J. Application of damage concepts to predict creep-fatigue failures. J. Eng. Mater. Technol. ASME 1979, 101, 284-292. [CrossRef]

21. Lemaitre, J. A continuous damage mechanics model for ductile fracture. J. Eng. Mater. Technol. 1985, 107, 83-89. [CrossRef]

22. Lemaitre, J. Anisotropic damage law of evolution. European. J. Mech. A Solids 2000, 19, 187-208. [CrossRef]

23. Krajcinovic, D. Continuum damage mechanics. Appl. Mech. Rev. 1984, 37, 1-6. [CrossRef]

24. Sidoroff, F. Description of anisotropic damage application to elasticity. In IUTAM Colloquium on Physical Nonlinearities in Structural Analysis; Springer: Berlin/Heidelberg, Germany, 1981; pp. 237-244.

25. Supartono, F.; Sidoroff, F. Anisotropic Damage Modeling for Brittle Elastic Materials. Arch. Mech. 1984, 37, 521-534.

26. Chaboche, J.L. Continuum damage mechanics: Present state and future trends. Nucl. Eng. Des. 1987, 105, 19-33. [CrossRef]

27. Chaboche, J.L. The concept of effective stress applied to elasticity and viscoplasticity in the presence of anisotropic damage. In Mechanical Behavior of Anisotropic Solids; Boehler, J.-P., Ed.; Martinus Nijhoff: The Hague, The Netherlands, 1982; pp. 737-760.

28. Bazant, Z.P. Mathematical model for freeze-thaw durability of concrete. J. Am. Ceram. Soc. 1988, 71, 776-783. [CrossRef]

29. Cai, H. Prediction Model of Concrete Frost Resistance Durability; Tsinghua University: Beijing, China, 1998.

30. Xu, L.P.; Wu, X.L.; Huang, S.Y. Design of frost resistant concrete. J. Shanghai Inst. Build. Mater. 1998, 6, $112-123$.

31. Cheng, X.W. Application of redispersible latex powder in tunnel fire retardant coating. New Build. Mater. 2006, 2, 41-42.

32. Cheng, X.W. Preparation and Characterization of Tunnel Fire Retardant Coating; Sichuan University: Chengdu, China, 2005.

33. Chen, S. Research progress of tunnel fire protection. Coat. Technol. Abstr. 2008, 29, 7-9.

34. Liao, C.; Ji, T.; Jiang, Q.D. Study on bonding properties of tunnel fire retardant coating under freeze-thaw cycles. J. Fuzhou Univ. (Nat. Sci. Ed.) 2015, 43, 245-248.

35. GB National Standard. Test Method Standard for Long Term Performance and Durability of Ordinary Concrete; Ministry of Housing and Urban Rural Development of the People's Republic of China: Beijing, China, 2009; GB/T 50082-2009.

36. GB National Standard. Multi Layer Architectural Coatings. General Administration of Quality Supervision; Inspection and Quarantine of the People's Republic of China: Beijing, China, 2015; GB/T 9779-2015. 